\title{
EL CLAN CHIARINI: MIGRACIÓN Y FALSIFICACIÓN DE DINERO EN AMÉRICA DEL SUR, 1890-1910 \\ Diego Galeano ${ }^{1}$ \\ Pontificia Universidade Católica do Rio de Janeiro
}

INTRODUCCIÓN

G $\mathrm{n}$ julio de 1905 se entrenó en el teatro Rivadavia de Buenos EAires la obra Marco Severi, drama en tres actos escrito por el periodista Roberto Payró, que terminó siendo un éxito de taquilla. El protagonista era un inmigrante italiano conocido como Luis Vernengo, dueño de una imprenta y casado con una criolla. Vivía acosado por el temor a que un pedido de extradición del gobierno italiano revelara su identidad. Luego de descubrir que el tipógrafo de su taller era un agente de pesquisa y que la policía lo vigilaba, decidió confesarlo todo ante su esposa en un monólogo del segundo acto: su verdadero nombre era

Fecha de recepción: 15 de enero de 2020

Fecha de aceptación: 1을 mayo de 2020

${ }^{1}$ Este texto fue escrito a fines de 2019 durante una estadía en el Munich Centre for Global History (Ludwig-Maximilians-Universität München). Agradezco a esa institución la posibilidad de dedicarme íntegramente a la investigación gracias a su programa de becas de corta duración en historia global. 
Marco Severi y había llegado a la Argentina como prófugo de la justicia italiana, tras ser condenado por falsificación de dinero. Trabajaba en una imprenta de Roma y -como muchos obreros tipográficos a fines del siglo XIX- "había sido anarquista lírico, por exceso de juventud”, según le hacía decir Payró. Al saber que su madre estaba enferma y necesitaba dinero, un compañero del taller le propuso entrar en el negocio de la falsificación de billetes de banco, para encargarse de grabar las planchas litográficas. Cuando la fábrica fue descubierta por la policía romana, pudo escaparse disfrazado hasta el puerto de Génova y embarcar a Buenos Aires. En la capital argentina se enteró por los diarios del desenlace del proceso judicial, que lo condenaba a "largos años de presidio".2

Esta historia reunía varios elementos habituales en el repertorio de las ficciones de inmigrantes de la Argentina del cambio de siglo: el ascenso social, la simulación de identidad y el inquietante pasado europeo de los extranjeros que se casaban con mujeres del país. ${ }^{3}$ Si esos recursos narrativos alimentaron el interés por la obra teatral de Payró, la elección de la falsificación de dinero como mácula en el prontuario del italiano no debe ser pasada por alto. En esos años, sus espectadores tenían a su disposición una enorme cantidad de reportajes periodísticos sobre bandas de falsificadores de billetes, compuestas en su mayoría por fotógrafos, grabadores y tipógrafos de origen europeo. Ante los ojos de lectores de diarios y espectadores de teatro, la vida económica del papel moneda y el drama matrimonial estaban atravesados por las mismas tensiones entre lo verdadero y lo falso, lo aparente y lo real, lo confiable y lo engañoso.

Este artículo propone investigar el vínculo entre migración, comercio y redes delictivas en América del Sur a finales del siglo xIX y primeras décadas del xx. A partir de la trayectoria

2 Payró, Marco Severi, pp. 49-53.

3 Laera, “Representaciones obliteradas”, pp. 231-253. 
atlántica de una familia de inmigrantes italianos involucrados en el mercado de la fabricación y circulación de dinero falso, busca iluminar una práctica tan rentable como riesgosa, proponiendo leerla en los términos en que sus protagonistas la leían: mediante un lenguaje del mundo de los negocios, con un vocabulario que llamaba "mercadería" a los billetes falsos, "capitalistas" a los inversores y "clientes" a los compradores. Desde una perspectiva de historia social, el texto dialoga con otros trabajos que sugieren estudiar determinados delitos -entre ellos, la falsificación de dinero- como un mercado ilegal. ${ }^{4}$

La trayectoria de esta familia es "atlántica" por la propia migración, pero también por los constantes viajes entre Argentina, Uruguay y Brasil. Como tratará de mostrarse por medio de sucesivas variaciones de escalas, el clan Chiarini era solamente un fragmento de una red mercantil y delictiva que conectaba a las ciudades del espacio atlántico sudamericano, las mismas que recibían a la mayoría de los inmigrantes europeos radicados en la región. El nexo entre inmigración y delito no es un tópico novedoso para la historiografía y la sociología criminal de América Latina. La mayor parte de los estudios existentes se enfocaron en las representaciones científicas, periodísticas y literarias, con especial énfasis en la historia del pensamiento criminológico. ${ }^{5}$ Otros trabajos más recientes indagaron en los sentidos de la justicia y en las disputas de honra a partir de procesos criminales por delitos contra las personas dentro de espacios migratorios. ${ }^{6}$ Menos preguntas se han hecho acerca del delito como parte de

\footnotetext{
${ }^{4}$ Hobвs, Doing the Business, y Johnson, Illegal Tender.

${ }^{5}$ Solo a modo de ejemplo, véanse Fausto, Crime a cotidiano, pp. 71-81; Salvatore, "Sobre el surgimiento del estado médico-legal en la Argentina"; Creazzo, El positivismo criminológico italiano en la Argentina; SCARZANELla, Ni gringos ni indios y Sozzo, "Los exóticos del crimen".

6 Por ejemplo, Vendrame, O poder na aldeia, y Bjerg, "Matrimonios malogrados y pasiones iracundas".
} 
las estrategias de supervivencia de los propios inmigrantes y su relación con las formas legales e ilegales de obtener lucro. ${ }^{7}$

"El motivo más importante que llevó a cientos de miles de italianos a emigrar era ganar dinero", escribía Samuel Baily en un ensayo comparado sobre las estrategias económicas de los italianos en Buenos Aires y Nueva York. ${ }^{8}$ Aunque sin indagar demasiado en los significados y usos sociales del dinero por parte de estos inmigrantes, Baily destaca la centralidad de las prácticas de acumulación, ahorro y giros monetarios en la empresa migratoria. En ese mundo de expectativas de ganancia y ascenso social, el dinero circulaba a gran velocidad: en casas de cambio y de empeño, en agencias de pasajes, en comercios, prostíbulos y cambalaches, en remesas a Italia por vía postal y bancaria. Estas variopintas transacciones monetarias, que transcurrían dentro, fuera y en las fronteras de la legalidad, ponían en juego relaciones de confianza, afectos y expectativas de futuro. Más que formar parte de una subcultura aislada, el mercado de la falsificación y sus oportunidades de lucro integraban los distintos mundos del dinero en los circuitos migratorios.

Para poner a prueba esa hipótesis, el artículo se divide en tres partes. La primera se detiene en la figura de Francesco Chiarini, inmigrante italiano detenido en Buenos Aires a fines del siglo xIx por fabricar billetes falsos de la Argentina y del Brasil. Desde ese punto de observación, reconstruye la trama de actores abocados a la falsificación y a la persecución de este delito: los distintos participantes en la red de negocios y

7 La historia de la mafia en Estados Unidos puede ser señalada como un ejemplo de un campo de indagación prolífico sobre el vínculo entre inmigración, delito y economía. Véanse, por ejemplo, Catanzaro, El delito como empresa, y Gambetta, La mafia siciliana. Dentro de la bibliografía sobre América Latina puede consultarse, por ejemplo, BUnKER, "Le vol avec homicide de la bijouterie “La Profesa”" y Galeano, Delincuentes viajeros, pp. 181-209.

8 Baily, "Hacer la América", p. 57. Sobre los usos del dinero en los inmigrantes de Estados Unidos véase Zelizer, The Social Meaning of Money, pp. 86-97. 
sus clientes; los periodistas, policías, cónsules, comerciantes y agentes bancarios van entrando aquí en escena. La segunda parte analiza los meandros del mercado de los billetes falsos, con sus transacciones entre fabricantes, intermediarios y circuladores, siempre amenazadas por la vigilancia policial. En este negocio de alto riesgo, los vínculos de parentesco y las solidaridades étnicas desempeñaban un papel fundamental en la construcción de lazos de confianza que la policía buscaba quebrar tratando de captar delatores. De hecho, aunque la fabricación de billetes falsos fuera técnicamente la parte más compleja del proceso, la puesta en circulación terminaba siendo su dimensión más peligrosa e incierta. La última parte ingresa de lleno en esa cuestión de la mano del hijo del falsificador Chiarini, quien realizaba esa tarea en viajes regulares entre el Río de la Plata y ciudades del sudeste brasileño. En ese plano de la circulación del dinero falso, por otra parte, se refleja la construcción de redes interétnicas que, a medida que el negocio se expandía, también involucraban a comerciantes portugueses, españoles y franceses.

Al igual que el Marco Severi de Payró, Francesco Chiarini había migrado a la Argentina como fugitivo de la justicia italiana, atravesando su vida bajo el acoso de la policía y el fantasma de un pedido de extradición. Justamente esos problemas con la justicia, esas vigilancias policiales y redes consulares dejaron rastros preciosos para comprender el negocio de la falsificación de dinero. Siempre siguiendo al clan Chiarini como hilo conductor, el corpus documental de este trabajo se fue construyendo con archivos diplomáticos de Argentina y Brasil, diversas fuentes policiales y judiciales, folletos y prensa gráfica. Aunque anclado en el campo de la historia social del delito en América Latina, el diálogo de este trabajo con la historiografía de las migraciones europeas en el mundo atlántico es fundamental, en particular con la perspectiva microanalítica de las redes migratorias. Al destacar el papel de los lazos de parentesco y amistad en las estrategias económicas de los emigrados, por medio de 
mecanismos de apoyo monetario para el financiamiento del viaje y la inserción en las sociedades receptoras, este enfoque pone sobre la mesa preguntas relevantes para pensar las redes delictivas y sus tejidos de relaciones interpersonales. ${ }^{9}$ El mercado de los billetes falsos permite entrar en ese mundo atravesado por confianzas y desconfianzas, transacciones y traiciones, solidaridades étnicas, familiares y amicales.

\section{LA SUDAMERICANA DE BILLETES DE BANCO}

El 27 de febrero de 1899, el jefe de la policía de Buenos Aires, Francisco Beazley, le escribió una carta confidencial al embajador brasileño en la Argentina. Le contaba que la Comisaría de Investigaciones de esa ciudad había descubierto, dos días atrás, "un taller completo de falsificación de billetes de banco". Acudía a la vía consular para explicar que, en el allanamiento, se había "comprobado que se fabricaban billetes de la Nación [Argentina] y de los Estados Unidos del Brasil” de 50 y 100000 reis. El material secuestrado ascendía a la exorbitante suma de 8000 billetes de ambos valores y los autores, todos italianos, estaban presos. Por cartas secuestradas a los falsificadores, recibidas de Río de Janeiro y firmadas con seudónimos, Beazley presumía que se habían "remitido ya al Brasil algunas cantidades de esos billetes falsos" y consideraba demostradas las conexiones "con otros falsificadores o circuladores de ese país". ${ }^{10}$

El impacto económico de este delito puede intuirse en el circuito de autoridades involucradas y en la rapidez con que se

\footnotetext{
9 Sobre el impacto del enfoque de las redes sociales en la historiografía de las migraciones véase Ramella, "Por un uso fuerte del concepto de red en los estudios migratorios"; Ceva, "Inmigración y familia”; Devoto, Historia de la inmigración en la Argentina, pp. 122-159; OTERO, Historia de los franceses en la Argentina, pp. 165-175 y Borges, Correntes de Ouro, pp. 161-232.

10 AHI, Embajada de Buenos Aires, 206-1-10, Carta confidencial del jefe de la Policía de la Capital, Francisco Beazley (27 de febrero de 1899).
} 
movían, así como también en la atención prestada por los corresponsales al seleccionar las noticias que viajaban por los cables sudamericanos. El embajador perdió poco tiempo y mandó un telegrama al ministro de Relaciones Exteriores del Brasil, pidiendo que avisara a la policía de Río de Janeiro. En seguida preparó un envío postal más detallado, con la carta de Beazley, algunos ejemplares de los billetes falsos que le dio la policía porteña y recortes de los diarios. ${ }^{11}$ La prensa de Buenos Aires le había dedicado al caso extensas crónicas que ocupaban casi todo el espacio de sus columnas policiales. En una frenética carrera por primicias que, no pocas veces, suscitaba la ira de los detectives de la Comisaría de Investigaciones, los reporteros narraban pormenores de la pesquisa ausentes de la discreta carta de Beazley. Por ese motivo, al embajador los propios diarios le parecían un buen complemento en su tarea de informar al canciller.

Desde el día siguiente al allanamiento, los principales matutinos de Buenos Aires salieron a competir entre sí y a disputar terreno con la Comisaría de Investigaciones. Su máxima autoridad, Belisario Otamendi, delegó la pesquisa en el subcomisario José Gregorio Rossi, quien en gran medida había llegado a ese puesto gracias a recomendaciones de ascenso por éxitos detectivescos en falsificación de dinero. ${ }^{12}$ Ese verano de 1899 venía agitado para Rossi tras la aparición de una serie de billetes falsos de 100 pesos. No sólo los habían dado por buenos los cajeros de distintas casas comerciales, como solía ocurrir, sino que también los del Banco de la Nación, el Banco Español y el Banco de Italia. La luz de alarma se encendió en la prensa: “¡Sabe Dios cuántos billetes de $\$ 100$ andarán circulando, cuando hasta

11 AHI, Embajada de Buenos Aires, 206-1-10, Carta confidencial del embajador al Ministro de Relaciones Exteriores (28 de febrero de 1899).

12 Véase, por ejemplo, Policía de la Capital Federal, Memoria del año 1893-1894, p. 205. 
los mismos bancos los reciben como legítimos!”, exclamaba un cronista de La Nación. ${ }^{13}$

Otamendi y Rossi tomaron cartas en el asunto. Advirtieron que se trataba de un notable trabajo de falsificación con uso de los "procedimientos más adelantados del fotograbado". El único defecto era la nitidez de las líneas del retrato del prócer Manuel Belgrano. No era una torpeza de la "mano del grabador” sino del proceso de impresión: en general, los clichés de las técnicas de fotolitografía empleadas en estas falsificaciones artesanales de papel moneda eran más defectuosos que la impresión directa de las planchas de acero, utilizadas por las casas emisoras. Pero esas diferencias sólo eran visibles para un "ojo experto" y -agregaba el periodista- "los expertos son pocos". Idéntica observación encontraban los lectores de La Prensa: "sólo podría distinguirla un perito en artes gráficas, que conozca a primera vista la nitidez de un grabado sobre acero y la diferencia que existe con el que se efectúa por medio de la fototipia”. ${ }^{14}$

Cuando estalló el caso que reveló conexiones con Brasil, el subcomisario Rossi acababa de retornar de Montevideo por una misión vinculada a esta falsificación de billetes de 100 pesos. Un "viejo circulador de billetes falsos, habituado a los contratiempos que produce esta clase de negocios" había sido detenido por la policía uruguaya y Rossi cruzó el Río de la Plata para interrogarlo. Sospechaba que provenían de una fábrica en Italia. ${ }^{15}$ Lo que terminó descubriendo en los días siguientes fue una red de inmigrantes italianos que producían dinero falso de Argentina y del Brasil en un taller localizado en un suburbio de Buenos Aires. A esa altura, Rossi tenía bajo sus órdenes a varios agentes de pesquisa repartidos en distintos puntos de la

13 “Nota de alarma”, La Nación (27 ene. 1899).

14 “Policía. La nueva falsificación”, La Nación (28 ene. 1899) y "Noticias de Policía. Nueva falsificación de billetes de banco”, La Prensa (27 ene. 1899).

15 “Noticias de Policía. La falsificación de billetes de 100 pesos”, La Prensa (2 feb. 1899). 
ciudad para seguir la pista de un italiano considerado el "más famoso de los circuladores de billetes falsos" y conocido como Julio Ricardi, aunque su nombre de nacimiento era Francesco Chiarini. ${ }^{16}$

La Comisaría de Investigaciones tenía en la mira a la colectividad italiana como responsable por la circulación de dinero falso en Buenos Aires. En un informe anual de sus actividades, Otamendi utilizaba a la falsificación de dinero como un ejemplo de la eficacia de centralizar la vigilancia de ciertos tipos de delitos, en lugar de dejarla en manos de los distintos comisarios seccionales. A lo largo de 1897 -explicaba-se habían constatado ocho falsificaciones de dinero, la mitad de las cuales terminaron con allanamientos en las fábricas, secuestros de maquinarias y prisión de los delincuentes. Eso contrastaba con una tasa anterior mucho más baja: $26 \%$ de fábricas descubiertas por distintas autoridades, de un total de " 56 falsificaciones de billetes [del Banco] de la Nación [realizadas] dentro y fuera del país" entre 1890 y 1897 . La mejoría de los resultados tenía un responsable con nombre y apellido:

Diez agentes a las órdenes de un empleado competente, don José G. Rossi, son los encargados de vigilar esa enorme cantidad de falsificadores y circuladores de moneda que se distinguen por $\mathrm{co}^{-}$ lonias. La piacentina es la más numerosa y peligrosa, siguiéndole la romañola y la napolitana. Esta última es casi exclusiva en moneda de emisión menor, que colocan entre los vendedores ambulantes de verdura y pescado y en negocios de última categoría. La colonia piacentina, compuesta de individuos, muchos de los cuales tienen algún capital, son los compradores al por mayor de gran parte de las falsificaciones y principalmente de las que se hacen en el extranjero. Es frecuente entre los piacentinos acaparar billetes cuando

16 “Policía. La gran falsificación descubierta”, La Nación (26 feb. 1899). 
están en abundancia, para revenderlos luego que la mercadería escasea en la plaza. ${ }^{17}$

Es probable que esta nomenclatura revelara más bien taxonomías policiales que expresiones del lenguaje nativo de los falsificadores. El uso de la noción de “colonia” y la alusión a regiones de Italia era una referencia directa al mundo de los inmigrantes. La asociación entre migración y delito formaba parte del sentido común de los agentes de investigaciones. En un artículo para la revista Archivos de Psiquiatría y Criminología, el propio Rossi empleaba el concepto de "colonia lunfarda" para denominar a los 15 o 20000 "delincuentes profesionales" que residían en Buenos Aires. "Abierta de par en par” a la corriente migratoria, la ciudad recibía punguistas, estafadores y "falsificadores que, como obreros, podrían honrar a la mejor de nuestras casas de grabado o litografía”. ${ }^{18}$ Entre fabricantes y circuladores de billetes falsos, explicaba Rossi, los archivos de la Comisaría de Investigaciones acumulaban fichas de 1500 falsificadores conocidos, la mayoría extranjeros.

La persecución de Francesco Chiarini y sus cómplices empezó por ese archivo. Ante la sospecha que apuntaba a una red de migrantes italianos, los agentes de pesquisas siguieron los pasos de sujetos de esa nacionalidad fichados como circuladores de billetes. Chiarini no fue el único, ni el primero. De hecho, el hilo que permitió desentrañar la madeja surgió de la observación de los movimientos de un tal "Cosmín”, Cosme della Giovana, quien acumulaba tres entradas en la policía por falsificación de dinero. Los agentes camuflados notaron que, durante la noche, Cosmín salía a la puerta de su casa sobre la calle Mansilla y un mismo sujeto pasaba sin mirarlo ni saludarlo.

17 "Policía de la Capital. Retrospectivo del año 1897", en Revista de Policía, 15 (10 ene. 1898), pp. 274-275 [letra itálica en el original].

18 Rossi, "La criminalidad profesional en Buenos Aires", p. 173. 
Se encontraban a dos o tres cuadras, intercambiaban algunas palabras y un paquete. ${ }^{19}$

Ese sujeto era Francesco Chiarini, versado en la tarea de despistar a la policía. Aun cuando no tuviera indicios de estar siendo perseguido, tomaba un tranvía, se bajaba pocas cuadras después de subirse y entraba en otro coche en la dirección opuesta. Muchas veces se escabullía entre la muchedumbre de las estaciones de Once y Constitución, o entraba en la Bolsa de Comercio atravesando puertas diversas. La policía conocía esta práctica elusiva como "esquinazo". Rossi no se dio por vencido y puso más de 20 agentes disfrazados para vigilarlo, desparramados por distintos lugares que frecuentaba. El 22 de febrero lograron seguirle los pasos hasta que entró a una casa sobre la calle Piedad. Recién salió en la madrugada del día siguiente, "con un traje casi de atorrante y todo sucio", lo que despertó las sospechas de Rossi, porque Chiarini solía ser un hombre elegante. Lo persiguieron hasta otra casa en el más alejado barrio de Belgrano. La clave era vigilar y reunir indicios suficientes para convencer a un juez de una orden de allanamiento, sin que los falsificadores lo notaran. Cada vez que Chiarini salía de una de las propiedades vigiladas, los agentes se hacían "perdiz entre los yuyos". ${ }^{20}$

Un día la orden judicial llegó: el 25 de febrero, alrededor de las 10 de la mañana, la manzana de la casa de Belgrano fue rodeada por numerosos agentes. La plana mayor de la Comisaría de Investigaciones se hizo presente, con Otamendi y Rossi a la cabeza. Este último golpeó la puerta y una señora salió a abrir. En ese momento, algunos agentes vigilaban el fondo de la casa, otros las alturas desde la azotea, mientras los demás acompañaban a Rossi dentro de la vivienda. Los falsificadores estaban en pleno trabajo y trataron de huir, pero fue en vano. Terminaron

19 "Noticias de Policía. La gran falsificación descubierta”, La Prensa (27 feb. 1899).

20 "Policía. La gran falsificación descubierta”, La Nación (26 feb. 1899). 
presos con sus "trajes de taller" y con sus "manos sucias de tintas litográficas”. Todo estaba en su lugar y todo fue aprehendido: prensas y piedras litográficas grabadas, máquinas fotográficas, placas de negativo en cristal, tintas de diversos colores, una estufa secadora y frascos con productos químicos. Las paredes del taller estaban cubiertas de billetes falsos todavía húmedos, colgados en hilos dispuestos horizontalmente para el proceso de secado. También había cajones con billetes de pesos argentinos listos y empaquetados, otros con billetes inconclusos y descartados por fallas. Para completar lo que al obstinado Rossi le debe haber parecido un tesoro de pruebas, se encontró una biblioteca con diversos volúmenes sobre las artes gráficas. Días después, el rutilante "triunfo de la policía” fue objeto de un reportaje del semanario Caras y Caretas, con imágenes del interior de la fábrica, de los protagonistas de la investigación y de las escenas del allanamiento. Es evidente que un fotógrafo del magazine había sido avisado por la policía, mostrando la faceta más cooperativa entre la prensa gráfica y la Comisaría de Investigaciones: primicias a cambio de publicidad de las pesquisas.

Tres días después de esta crónica, el 7 de marzo de 1899, Rossi recibiría una nueva recomendación de ascenso. ${ }^{21}$ Aunque la promoción no sería inmediata, la suma de éxitos en casos de falsificación de dinero, que se encadenaron en los años siguientes, le valieron un salto en el escalafón a subcomisario en 1901 y la coronación como sucesor de Otamendi en el cargo de comisario de investigaciones, que mantuvo desde fines de 1902 hasta su retiro en 1916. ¿Por qué eran tan estratégicas en su carrera estas pesquisas para desarmar fábricas de billetes falsos? El caso Chiarini permite construir algunas respuestas. Es innegable que el interés del público lector, cada vez más ávido de crónicas policiales sensacionalistas, era un elemento central. Ante la ausencia

21 “José G. Rossi. Comisario de Investigaciones”, Boletín de Policía, 5, Buenos Aires (30 jun. 1905), p. 2. 


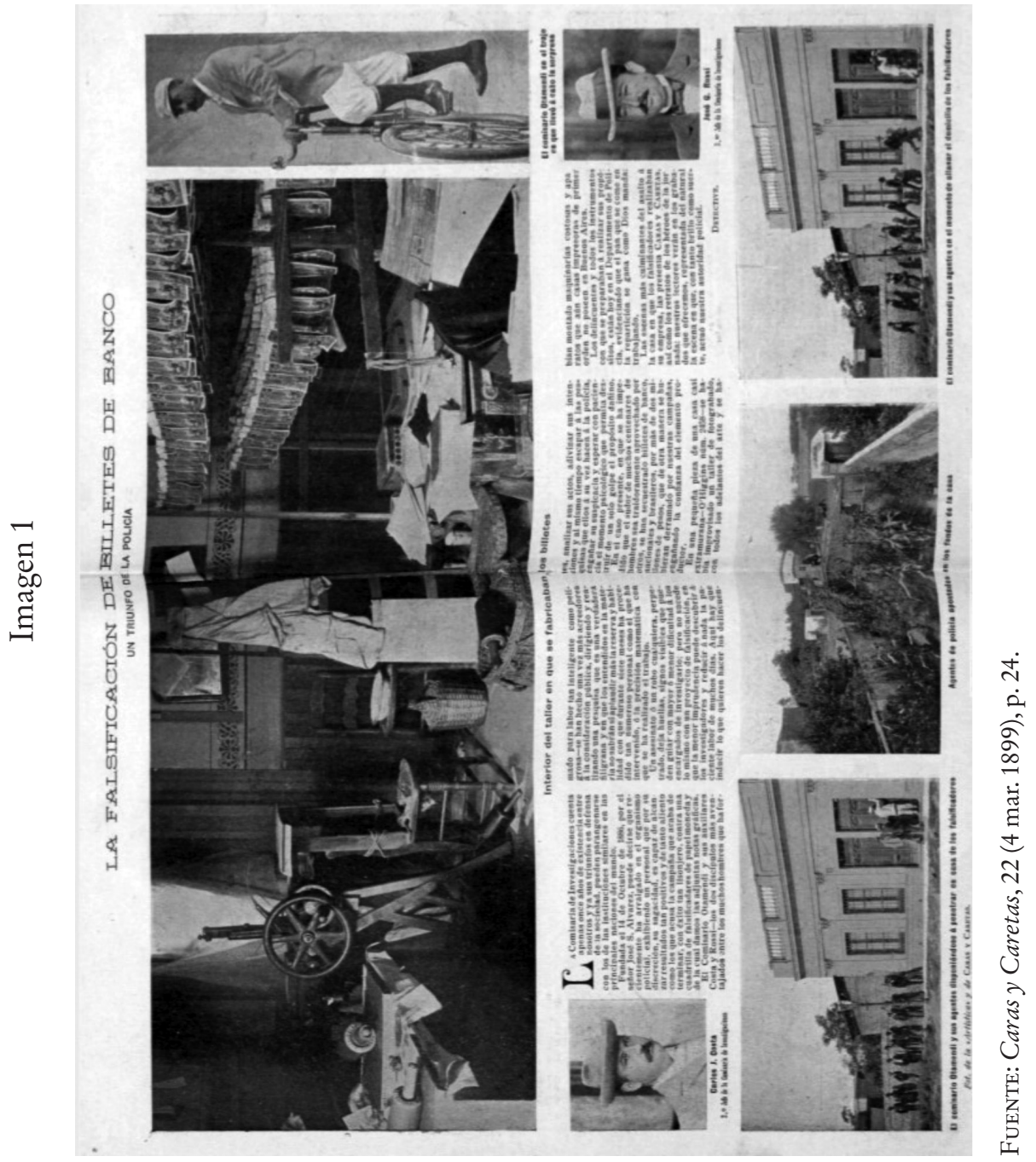


de primicias en los días posteriores al allanamiento, muchas de las notas periodísticas repetían lo sabido y prometían futuras novedades a sus lectores: "es posible que de hoy a mañana a más tardar pueda saberse algo", se leía en una suerte de pedido de disculpas al público. Otro indicador de ese interés eran las frecuentes visitas de los lectores a las salas de redacción de los diarios, que organizaban exhibiciones en el salón de avisos para mostrar las diferencias entre billetes falsos y legítimos. Más allá del voyerismo y de la atracción por las noticias sensacionales, el cronista de La Prensa registraba un interés más práctico del público, preocupado por "saber de qué manera puede librarse de recibir como buenos billetes que no tienen ningún valor". ${ }^{22}$

Esta pedagogía monetaria no se dio solamente en el caso Chiarini. A mediados del año siguiente, una nueva falsificación descubierta por Rossi suscitó la misma reacción del diario La Prensa, que expuso dos billetes falsos de 500 pesos y dos legítimos a fin de ser "comparados por el anverso y el reverso". Para aquellos que no podían acercarse al edificio de la redacción se brindaban detalles en las propias columnas policiales: en la figura de la mujer los dedos del pie izquierdo eran defectuosos, en el retrato del prócer el pelo que caía sobre la frente era diferente del original y la nariz era "demasiado aguileña”. El diario explicaba que, cada tanto, los periodistas aprovechaban la presencia del "numeroso público que afluía a verificar las diferencias" y fijaban en el salón informaciones con novedades sobre la investigación policial..$^{23}$

Además de los trabajadores que se acercaban a la redacción de los diarios con la esperanza de evitar que el salario se esfumara en la vergonzosa incautación de un billete falso, otros

22 “Noticias de Policía. La falsificación de billetes”, La Prensa (1o mar. 1899) y "Noticias de Policía. Los billetes falsificados", La Prensa (4 mar. 1899).

23 "Falsificación de billetes de 500 pesos", La Prensa (27 mayo 1900) y "Las falsificaciones de billetes de banco. Los de 500 pesos", La Prensa (28 mayo 1900). 
tres actores desplegaban un repertorio de intervenciones más enérgicas en el combate de la falsificación. En primer lugar, los dueños de establecimientos comerciales. La circulación de dinero falso en la ciudad -escribía un cronista de La Nación-se había convertido en una "desesperación para el comercio", ya bastante afectado por la crisis de $1890 .{ }^{24}$ Entre los múltiples ejemplos de esta preocupación uno es ciertamente significativo y contundente: a pocos días de la detención de Chiarini y sus cómplices, un "numeroso grupo de comerciantes" entró en contacto con la jefatura de policía para pedirle autorización de una colecta que "se destinaría a la compra de un inmueble para regalar al subcomisario Rossi, con motivo de la brillante pesquisa que efectuó últimamente". Aunque no queda claro si le compraron la casa a Rossi, la iniciativa contaba con una fuerte base de suscriptores y ya había reunido "una suma nada despreciable". ${ }^{25}$

Otro de los actores de peso en este juego del dinero falso eran los bancos. No era raro, por cierto, que los directorios de las entidades bancarias pagaran a los agentes de investigaciones jugosas "recompensas" por descubrir a los autores de asaltos a sus sucursales, como sucedió con el propio Rossi. ${ }^{26}$ Por el secreto con que manejaban sus cuentas, es difícil calcular las pérdidas de los bancos cuando sus empleados dejaban pasar billetes falsos en las transacciones. Pero sobran indicios cualitativos sobre los estragos, económicos y fiduciarios, que generaban falsificaciones sofisticadas como la de Chiarini. En este caso, ni siquiera el auxilio de los peritos de la Caja de Conversión había logrado evitar que diversos bancos públicos y privados aceptaran billetes falsos. "Los empleados -escribía un cronista de $\mathrm{La} \mathrm{Na}$ ción- poco han observado los billetes" y lejos estaban de "ser conocedores del arte tipográfico, litográfico, fotográfico, del

\footnotetext{
24 "Policía. La gran falsificación descubierta”, La Nación (26 feb. 1899).

25 "Noticias de Policía. Ecos de la falsificación", La Prensa (5 mar. 1899).

26 "Sueltos. El subcomisario José G. Rossi”, Revista de Policía, 58 (15 oct. 1899), p. 159.
} 
fotograbado". ${ }^{27}$ De alguna manera, la "brigada" liderada por Rossi en la Comisaría de Investigaciones buscaba ocupar ese espacio vacío que dejaba la ausencia de peritos en artes gráficas en los bancos y en la propia Caja de Conversión, recién creada para constituirse como autoridad estatal en la emisión de moneda.

Por último, cabe señalar un tercer actor clave: los embajadores y cónsules que integraban los circuitos diplomáticos de los países afectados por la moneda falsa fabricada en el Río de la Plata. Según las crónicas, mientras Chiarini era interrogado por el juez federal, a altas horas de la noche, el embajador brasileño estaba presente en el Departamento de Policía para felicitar a los agentes de investigaciones "por el éxito de la brillante pesquisa que tan directamente interesa a su país". Esa misma noche el diplomático le mandaría el telegrama a su canciller y al día siguiente despacharía por correo todo lo demás, con los ejemplares de los billetes falsos que le obsequiaron los policías argentinos. ${ }^{28} \mathrm{El}$ archivo histórico del Ministerio de Relaciones Exteriores del Brasil muestra -como se verá a continuación-el activo papel del embajador en Buenos Aires en la circulación de informaciones sobre estas redes de falsificación de moneda brasileña con raíces en la capital argentina, a lo largo de la última década del siglo xIx y comienzos del xx. ${ }^{29}$

Lo cierto es que el caso Chiarini tuvo tanto impacto en la prensa porteña que el periodista y humorista gráfico Eustaquio Pellicer, fundador del magazine Caras y Caretas, le dedicó uno de sus relatos de misceláneas de actualidad. La "importante fábrica de papel moneda" descubierta por la policía se le antojaba comparable con la sociedad anónima Sudamericana de Billetes de Banco. Pese al tono sarcástico de todo el relato, la comparación con una empresa de industria gráfica dedicada a

\footnotetext{
27 “Policía. La falsificación”, La Nación (4 mar. 1899).

28 "La falsificación”, La Nación (28 feb. 1899).

${ }^{29}$ Sobre el papel de los diplomáticos brasileños en el combate de la falsificación en Buenos Aires, véase también Galeano, "Ese derrame extraordinario".
} 
la impresión de estampillas y cédulas bancarias no era casual. Pellicer trataba a la falsificación de dinero como un negocio y así lo hacía en un diálogo hipotético entre los fabricantes y su clientela:

- Necesito diez contos de reis en papel, para establecerme de rentista en Río de Janeiro.

- ¿De qué emisión los quiere?

- De cualquiera, con tal de que esté bien imitada.

- Aquí, señor, no se engaña a nadie en punto a buenas imitaciones. Todos nuestros billetes son de superior calidad, y la prueba es que no usamos de otros para nuestros pagos.

- ¿Cuánto me va a costar?

- La quinta parte de su valor, en billetes fabricados para el gobierno.

- ¿Y por qué se ha de pagar en esos billetes y no en los de ustedes?

- Porque no se crea que despreciamos los productos de nuestros colegas. Es un acto de compañerismo.

- Aplaudo esa delicadeza y acepto el trato. ¿Me tendrán pronto lista esa plata?

- Pues mire usted, hasta dentro de diez o doce días no podrá ser, porque estamos imprimiendo con mucho apuro cien mil pesos en moneda oriental para un comerciante fundido en Montevideo. ${ }^{30}$

Cargado de una ironía no exenta de cierta condena moral contra los falsificadores, el relato de Pellicer debe ser comprendido en su contexto inmediato. Durante el gobierno de Juárez Celman, en los años anteriores a la crisis financiera de 1890, la emisión monetaria estaba descentralizada en distintos bancos, a los que sólo se les exigía como garantía un depósito en oro como respaldo. Tras el colapso bancario de 1891, la facultad de emitir dinero fue transferida a la Caja de Conversión, que además se encargó de sacar de circulación e incinerar los billetes

30 Eustaquio Pellicer, “Sinfonía”, Caras y Caretas, 22 (4 mar. 1899), p. 30. 
“inconvertibles”. En este marco se firmó un contrato entre la Caja de Conversión y la Compañía Sudamericana de Billetes de Banco para la impresión del nuevo dinero de curso legal. Sin embargo, hasta comienzos del siglo xx, hubo una pronunciada contracción de la oferta monetaria y una reducción de la capacidad bancaria para otorgar créditos, que afectó seriamente al comercio. ${ }^{31}$ De esta manera, la comparación de los fabricantes de dinero falso con la sociedad anónima encargada de imprimir los billetes legítimos adquiere sentidos más nítidos cuando recordamos que, en estos años, el comisario Otamendi comentaba que los circuladores italianos de moneda falsa actuaban cuando "la mercadería escasea en la plaza”.

Pellicer parecía bien informado sobre los detalles de este negocio del dinero falso y bromeaba al pedir que se respetara el "libre ejercicio" de esta industria que representaba tan bien los adelantos en las artes gráficas. Al fin y al cabo, se preguntaba, por qué castigar al artesano que, por falta de dinero, apelaba al recurso de fabricarlo. Lo que no mencionaba es que todos los socios de esta empresa, que el periodista bautizaba "marca Chiarini y Compañía”, eran migrantes italianos. En el fallo, el juez federal procesó a siete de ellos, casi todos rondando los 40 años de edad y una década de residencia en la Argentina. La mayoría eran casados y comerciantes: el propio Francesco Chiarini aparecía registrado como "corredor de vinos". ${ }^{32}$

A la luz de estas evidencias, la referencia de Otamendi sobre las colonias italianas de fabricantes y circuladores de billetes falsos puede ser releída a contrapelo. Es decir, no tanto para

31 Regalsky, “Modernización, expansión y crisis”. El contrato entre la Caja de Conversión y la Compañía Sudamericana de Billetes de Banco de 1895 puede consultarse en Ministerio de Hacienda de la Nación, Leyes, decretos y resoluciones sobre la moneda, p. 247.

32 "Causa criminal contra Enrique Caldelari y otros por falsificación de billetes de curso legal”, en Suprema Corte de Justicia de la Nación, Fallos de la Corte Suprema de Justicia, pp. 418-421. 
precipitarse hacia la afirmación de la existencia de bandas organizadas por círculos étnicos, sino para dirigir la mirada hacia el mundo de los migrantes dedicados al comercio y sus dilemas en la lucha cotidiana por juntar dinero. Había en estas redes, por otra parte, más cruces entre nacionalidades de los que admitía Otamendi: por ejemplo, uno de los italianos condenados junto con Chiarini en 1899, el también comerciante Arnoldo Pedretti, reaparecería como cómplice en una fabricación de billetes brasileños liderada en 1911 por el francés Georges Raimbault. ${ }^{33}$ Si se enlaza el comentario de Otamendi sobre la puesta en circulación de billetes falsos en épocas de iliquidez con la alusión de Pellicer a un "comerciante fundido en Montevideo" como cliente de la fábrica, salta a la vista que la práctica de falsificar y circular dinero falso puede ser comprendida en la superficie de la economía cotidiana del comercio y no sólo en los submundos del delito.

\section{“MIENTRAS LAS PRENSAS RODABAN"}

Cuando Francesco Chiarini aguardaba su juicio en la prisión, llegó a la Argentina un pedido de extradición enviado por el gobierno italiano. En el Archivo del Ministerio de Relaciones Exteriores pueden encontrarse rastros que dejó el trámite en su camino al juzgado federal. El pedido, elevado por el cónsul de Italia el 31 de agosto de 1900, brinda algunos datos de la trayectoria de vida de Chiarini. Nacido el 16 de marzo de 1850 en la ciudad italiana de Faenza, había sido condenado en 1890 por un tribunal de la provincia de Rávena a diez años de reclusión por quiebra fraudulenta. ${ }^{34}$ Los registros de entrada de barcos

33 Sobre la participación de Pedretti en esa falsificación de 1911 y la trayectoria de Raimbault, véase GalEano, "Un artista del delito", p. 220.

${ }^{34}$ AMRE, Legaciones y Consulados en Europa -Italia- 1900, c. 737, Extradición de Francisco Chiarini, 15 septiembre 1900. Diarios de Río de Janeiro se hicieron eco del trámite de extradición y contaban que el gobierno argentino pretendía hacer lugar al pedido italiano, pero que sólo podría cumplirse 
en el puerto de Buenos Aires, por su parte, muestran que un Francesco Chiarini ingresó a la Argentina el 5 de octubre de 1890, en el vapor Città di Genova. La proximidad de la fecha y la edad declarada ante las autoridades argentinas (41 años) tornan verosímil la hipótesis de una huida de Italia para evitar la prisión a la que estaba condenado, al igual que el falsificador de la obra de teatro de Payró. ${ }^{35}$

Poco después de ser objeto del pedido de extradición, el nombre de Chiarini volvió a las columnas policiales. Esta vez, había sido sorprendido en su celda de la Penitenciaría Nacional con unas copias de billetes falsos brasileños y argentinos. Desde hacía un tiempo, el gobernador de la cárcel sospechaba que Chiarini mantenía relaciones con falsificadores sueltos en la ciudad y dispuso una vigilancia especial sobre el preso italiano. A comienzos de noviembre de 1900, Chiarini recibió una carta y, mientras la abría, un guardia lo observaba desde una celda contigua. Según la versión de los diarios, el vigilante notó que dentro del sobre había un billete de un peso, que Chiarini ocultó en un colchón. Los agentes penitenciarios requisaron la celda. En el colchón encontraron, además del peso, una copia sin terminar de un billete del Brasil. En el interrogatorio, Chiarini negó cualquier responsabilidad y declaró que el colchón lo había obtenido de otro preso. Ni los carceleros ni los periodistas le creían: "dados los antecedentes que se tienen de Chiarini y su gran habilidad para la preparación de trabajos de litografía”, comentaba el cronista de La Prensa, todos sospechaban que el italiano "inició y dirigió desde su celda el trabajo de los billetes falsificados, que bien pueden formar parte de la falsificación de

después del juicio y, eventualmente, de cumplir su condena: "República Argentina. Extradição", A Imprensa (13 nov. 1900) y "Notas falsas. Preso falsificador", Jornal do Brasil (12 nov. 1900).

35 Estos registros portuarios constan en la base de datos del CEMLA [https:// cemla.com]. Consultado el 16 de diciembre de 2019. 
billetes descubierta por la policía en vísperas de la llegada del doctor Campos Salles". ${ }^{36}$

La referencia a la visita del presidente brasileño era significativa. Meses después de la detención de Chiarini, en agosto de 1899, el presidente argentino, Julio Roca, emprendía un viaje oficial a Río de Janeiro. Entre la nutrida comitiva iba el jefe de policía, acompañado de cuatro agentes de pesquisa. La intención de Beazley era reunirse con su par brasileño y establecer algunos acuerdos de canje de informaciones sobre los "delincuentes profesionales" que viajaban entre los puertos del espacio atlántico sudamericano. En una de esas reuniones, le entregó al jefe de la policía carioca -a modo de muestra de esas conexiones delictivas-algunos billetes falsos de 50000 reis. ${ }^{37} \mathrm{La}$ cercanía con el allanamiento en la casa de Belgrano y el valor nominal del papel moneda indican que eran parte de los millares de ejemplares secuestrados en la fábrica de Chiarini, tesoro del que también salieron los billetes que el embajador brasileño le había remitido por carta a su canciller. Estos papeles, ahora invalidados con la impresión de un sello que denunciaba su falsedad, terminaban así transitando entre autoridades gubernamentales que a veces los usaban como trofeo y otras como prueba de la gravedad del delito.

En efecto, cuando en octubre de 1900 la comitiva del presidente Campos Salles se preparaba para desembarcar en el puerto de Buenos Aires, en retribución a la visita anterior de Roca, la Comisaría de Investigaciones descubrió otro caso de falsificación de dinero brasileño. La brigada dedicada a vigilar lo que llamaban "el gremio de monederos falsos", a cargo del

36 "Noticias de Policía. En la Cárcel Penitenciaria. Un reincidente”, La Prensa (12 nov. 1900) y "Noticias de Policía. En la Cárcel Penitenciaria. Falsificación abortada", La Prensa (13 nov. 1900).

37 "Entrevista com o Dr. Beazley", Jornal do Commercio (10 ago. 1899). Sobre la visita de Beazley al Brasil véase Galeano, Delincuentes viajeros, pp. 143-152. 
subcomisario Rossi, venía siguiendo los pasos de un fotógrafo francés conocido como Víctor Tisson, excarcelado unos meses antes. ${ }^{38}$ Después de juntar pruebas y lograr una orden de allanamiento del juez federal para entrar en la casa que ocupaba, la policía encontró un taller con máquinas y placas litográficas para imprimir billetes de 100000 reis. ${ }^{39}$ No era una buena carta de bienvenida para el presidente Campos Salles, a días de iniciar su visita al país, como sugería el periodista que trataba de involucrar al preso Chiarini con esta fábrica extramuros.

No hay indicios de este vínculo, aunque es plausible porque Chiarini había compartido meses con Tisson en la misma cárcel. Es importante -sin embargo- detenerse en la propia sospecha sobre esas relaciones. En la voz de los policías, el uso de expresiones como "colonia" y "gremio de monederos falsos" podía leerse como una referencia a las solidaridades que conectaban el riesgoso mundo de la falsificación de dinero con los lazos de confianza dentro de las colectividades migratorias. Por detrás de estas redes delictivas que ligaban fotógrafos, dibujantes y grabadores europeos llegados a estas costas para "hacer la América” y entregados - por diversos motivos- al negocio de los billetes falsos, la policía y la prensa veían una gran banda organizada a escala sudamericana. Cada vez que la Comisaría de Investigaciones quitaba el velo de una fábrica, secuestraba cartas entre cómplices situados en distintas ciudades de Argentina, Brasil y Uruguay, siempre interpretadas como piezas de ese gigantesco rompecabezas, como sucedió en el caso Chiarini. ${ }^{40}$

La frondosa correspondencia postal entre fabricantes, distribuidores y compradores de billetes falsos es un dato que puede

38 Tisson había salido de la prisión tras cumplir una pena de seis años por una falsificación realizada en 1894 en colaboración con un grupo de fotógrafos y litógrafos franceses. Galeano, "Un artista del delito", p. 204.

39 "Monederos falsos. La última pesquisa”, La Prensa (11 oct. 1900) y "Policía. Falsificación de billetes brasileños”, La Nación (11 oct. 1900).

40 "La falsificación”, La Nación (28 feb. 1899). 
ser constatado en distintas fuentes documentales. Los archivos diplomáticos del Brasil, por ejemplo, preservan varios ejemplares de esas cartas, secuestradas en los allanamientos, interceptadas en las propias cajas de correo o entregadas por personas que decidían denunciar. Entre las comunicaciones recibidas de la embajada en Buenos Aires aparece una carta firmada en Montevideo el 31 de julio de 1899 por un tal Julio Martins, de bella caligrafía e impecable portugués. Era dirigida a un comerciante de Ponta Grossa, en el estado brasileño de Paraná. Le ofrecía una cierta suma de billetes falsos, que llamaba "mercadería", mientras que la transacción recibía el nombre de "negocio". Era un intercambio muy lucrativo: "algunas personas, que hoy ocupan un lugar destacado en la sociedad, deben su fortuna a medios parecidos", añadía. La "mercadería” se debía pagar al contado después de verificar la calidad de la falsificación, y el precio oscilaba entre 40 y $50 \%$ del valor nominal de los billetes, lo que dependía de la cantidad adquirida. La palabra que más se repetía en el texto era "confianza": el autor de la carta buscaba mostrarse como un hombre confiable, que a su vez creía en la discreción de su interlocutor, al que pedía dos consideraciones: que la respuesta fuera enviada a una dirección en la ciudad de Buenos Aires y que "escribiera en un sentido como si se tratara de otra clase de mercadería". ${ }^{41}$

En septiembre de 1901, al ministro de Relaciones Exteriores del Brasil le entregaron una nueva comunicación confidencial del embajador en Buenos Aires, acerca de otra pista de circulación de moneda falsa brasileña. Informaba que el gerente de una casa comercial de Buenos Aires había recibido dos cartas dirigidas desde Joinville, ciudad del estado de Santa Catarina, proponiéndole entrar en un negocio de falsificación y adjuntándole como muestra un billete falso de 20000 reis. El comerciante,

${ }^{41}$ AHI, Embajada de Buenos Aires, 206-1-10, Carta confidencial de Julio Martins a Reinaldo da Silveira Loureiro (31 jul. 1899). 
que denunció el hecho al consulado, aseguró desconocer al autor de las cartas. En esos días, el mismo embajador siguió la pista de un tal Evaristo Rodríguez, residente en Buenos Aires, quien le habría escrito a una importante casa comercial de Florianópolis, Oliveira Carvalho e Irmão, ofreciéndole billetes falsos del Brasil. ${ }^{42}$ Más tarde, entró en contacto nuevamente con el canciller para adjuntarle una nota que había recibido de Beazley: la policía porteña intervino la casilla de correo y el jefe explicaba que, después de las averiguaciones, quedó claro "que se trataba de cuenteros, delincuentes que escriben centenas de aquellas [cartas] ofreciendo billetes falsos para atraer las futuras víctimas, que resultan estafadas, pues en el acto del canje solo entregan paquetes inofensivos de papeles, bien acondicionados para el engaño". Pese a restarle importancia a este caso en particular, Beazley no dejaba de mostrarse activo en la persecución de los falsificadores de moneda brasileña:

Aprovecho la oportunidad para comunicar que la Comisaría de Investigaciones de esta policía ha descubierto en el día de ayer dos tentativas de falsificación de billetes de banco de vuestro país, de 5.000 y 100.000 reis, siendo aprendidos sus autores a quienes además se encontraron billetes falsificados de 200.000 reis y estampillas de $100,200,300$ y 1.000 reis. ${ }^{43}$

Uno de los detenidos en este caso de 1901 era el hijo de Francesco Chiarini. En este punto, una breve recapitulación es necesaria: dos años antes, en el allanamiento de la casa del barrio de Belgrano, junto con Chiarini y Cosmín cayeron presos también otros cuatro italianos: los hermanos Antonio y Luis Zeracini,

${ }^{42}$ AHI, Embajada de Buenos Aires, 206-1-11, Cartas confidenciales al Ministro de Relaciones Exteriores, Olinto de Magalhães (4 sep. 1901, 28 oct. 1901 y 1ㅇdic 1901).

43 AHI, Embajada de Buenos Aires, 206-1-11, copia del oficio del jefe de policía, Francisco Beazley (28 nov. 1901). 
un ingeniero naval llamado Arturo Orcessi, apuntado como el "capitalista” que financió la falsificación, y el joven Ricardo Chiarini. Al ser interrogado por la policía, Francesco buscó negociar una confesión a cambio de la libertad de su hijo Ricardo que -juraba- no tenía nada que ver con la fábrica de billetes falsos. Declaró que había "llegado el día de pagar por sus delitos" y, según las crónicas, se notaba una "verdadera aflicción en sus palabras, repitiendo que el menor era inocente". ${ }^{44}$

La trayectoria posterior de Ricardo Chiarini revela que estaba más cercano a este negocio de lo que Francesco quería mostrar. Nació en Italia alrededor de 1880, llegó a la Argentina después de su padre y, al ser detenido en el allanamiento de la casa de Belgrano, era un joven de algo menos de 20 años. ${ }^{45}$ En 1901, con Francesco dentro de la cárcel, su hijo caía junto con otros italianos en una nueva falsificación de billetes del Brasil, descubierta por la policía porteña tras una denuncia del embajador brasileño. Toda esta red comunicativa se había puesto en marcha cuando el gobierno del país vecino interceptó abundante correspondencia ofreciendo billetes falsos hechos en la capital argentina. Al seguir la pista y llegar a la fábrica, los agentes de pesquisa de Buenos Aires encontraron más cartas vinculadas al negocio, en las cuales los falsificadores se valían de un código para comunicarse con sus socios del Brasil.46

Los hilos que ataban a los Chiarini con otros fabricantes y circuladores de dinero falso en la región iluminan dos cuestiones fundamentales del negocio. La primera era la persistencia en esta

\footnotetext{
44 "Policía. La gran falsificación descubierta”, La Nación (26 feb. 1899) y "Noticias de Policía. La gran falsificación descubierta”, La Prensa (27 feb. 1899). 45 En el fallo del juez federal en 1899 , constaba que residía en la misma casa que su padre, sobre la calle Piedad, y que tenía 7 años de residencia en la Argentina, mientras Francesco Chiarini ya acumulaba una década. "Causa criminal contra Enrique Caldelari y otros", p. 419.

46 "Monederos falsos", La Prensa (28 nov. 1901) y "Falsificación de billetes del Brasil”, Caras y Caretas, 166 (7 dic. 1901), p. 30.
} 
actividad lucrativa pero riesgosa, que requería de mucho estudio de técnicas de fotolitografía y de impresión offset, operación de maquinarias complejas y conocimientos de química. Uno de los supuestos cómplices de la falsificación de 1899-que inicialmente logró huir, pero después fue detenido por la policía- era el español Enrique Pedro Caldelari, alias Lau-Lau. Al ser capturado, confesó su participación en el delito, constantes viajes al Brasil y acuerdos con Chiarini padre. En su casa, los agentes de pesquisa encontraron una gran biblioteca especializada en el campo de las artes gráficas, además de un "libro manuscrito, hecho de su puño y letra, que era todo un tratado de química". ${ }^{47}$ Experto en procesos fotográficos, preparación de reactivos y hábil dibujante, fluente en castellano, francés y portugués (el italiano lo manejaba apenas correctamente), Calderari era uno de los tantos inmigrantes europeos experimentados en el arte de fabricar dinero falso. Compartía con los demás la obstinación por mejorar la técnica y enfrentar los desafíos que llegaban con cada medida de seguridad tomada por las casas impresoras oficiales. En una falsificación de billetes de 50 pesos argentinos, de la que LauLau participó en 1896, el presidente de la Caja de Conversión tuvo que reunir a una comisión que discutió la posibilidad de cancelar y sacar de circulación toda la serie, porque era casi imposible distinguir los verdaderos de los falsos. ${ }^{48}$

La persistencia en el negocio -como veremos en la trayectoria de Ricardo Chiarini- podía cruzar una vida entera. "Pasión por el delito" y "la eterna historia de la reincidencia” eran fórmulas que periodistas y policías usaban para nominar lo que, en el fondo, no dejaba de ser un oficio, en el que se había invertido tiempo y dinero para tornarse especialista. Sin quitarles mérito y, algunas veces, sin esconder siquiera cierta admiración, sus vidas

47 “Noticias de Policía. La gran falsificación descubierta”, La Prensa (27 feb. 1899).

48 "Falsificación de billetes de 50 pesos", La Prensa (20 mayo 1896). 
eran narradas como efecto de una ceguera y de una obsesión irracional por el talismán dinero. Se escribía sobre la banda de Francesco Chiarini en 1899:

Nada los ha contenido y, enceguecidos en su fábrica, han continuado la tarea, ciegos, sin pensar más que en el mayor lucro, hasta que ayer han sido capturados con las manos en la masa mientras las prensas rodaban, mientras los cilindros con las tintas de colores se pasaban sobre las piedras, mientras se empaquetaban los billetes de las tres repúblicas. ${ }^{49}$

La alusión a los billetes de las "tres repúblicas" (Brasil, Argentina y Uruguay) conduce a la segunda cuestión. Cualquier mirada en las crónicas de la prensa, en la documentación judicial, policial y diplomática de esta época puede detectar la regularidad de las conexiones entre fabricantes y circuladores de dinero falso de esos países del Atlántico sudamericano. En consonancia con los indicios que transitaban por canales diplomáticos, la pesquisa encabezada por el subcomisario Rossi en 1899 comprobó que la falsificación venía siendo preparada desde hacía tiempo, con continuos viajes al Uruguay $\mathrm{y}$ al Brasil de los integrantes del negocio. En el allanamiento del domicilio particular de uno de los cómplices, Orcessi, se encontró abundante "correspondencia dirigida desde Río de Janeiro y Río Grande [do Sul], en la cual se pide envío de mercadería, palabra que se supone represente billetes falsos", explicaba un periodista. Esas cartas mostraban, además, remesas de dinero falso entre la fábrica de Chiarini en Buenos Aires y su "socio Orcessi" que estaba en el Brasil..$^{50}$ Muchos de los "socios" de su hijo en la falsificación de 1901 -como

49 “Policía. La gran falsificación descubierta”, La Nación (26 feb. 1899).

50 “La falsificación”, La Nación (27 feb. 1899) y “La falsificación”, La Nación (28 feb. 1899). 
Francisco Stumbo y Juan Segundo Scanzio- eran hombres de negocios que viajaban frecuentemente entre los puertos atlánticos sudamericanos, casi todos italianos residentes en los estados del sur y sudeste brasileño. Al igual que entre muchos otros inmigrantes, las redes de amistad y parentesco vertebraban esos grupos de negocios que -como revelaban las cartas secuestradas- se basaban en la confianza. ${ }^{51}$ Mercadería, socios, sucursales: a la par de la retórica policial sobre la existencia de una banda única y perfectamente organizada, aparecía también un lenguaje del mundo de los negocios. Mientras las prensas rodaban en los talleres clandestinos, se iba tejiendo toda una trama regional entre fabricantes, distribuidores y circuladores de dinero falso.

\section{MOEDEIRO FALSO FILHO DE MOEDEIRO FALSO}

El itinerario atlántico de Ricardo Chiarini en los primeros años del siglo xx es revelador de la intensidad de estas conexiones. Los permanentes viajes entre Buenos Aires, Montevideo, Santos y Río de Janeiro sugieren que se había convertido en una pieza clave en la distribución mayorista de billetes falsos. En 1905 fue preso varias veces en Río de Janeiro por sospechas de "introducir dolosamente moneda falsa", cuando usaba el nombre de Ricardo Kerry. Cierta vez lo detuvieron a bordo del barco, ni bien llegó al puerto, aunque no encontraron nada comprometedor después de revisar su equipaje. En otra ocasión fue interrogado en el Departamento Central de Policía. Declaró que era un comerciante con residencia en Buenos Aires y que viajaba

51 "Notas falsas", Jornal do Brasil (20 dic. 1901) y "Menudencias", Caras y Caretas, 173 (25 ene. 1902). Por otra parte, los emigrados y sus familias estaban habituados a las conversaciones postales sobre "asuntos de dinero" y diversos tipos de acuerdos monetarios, como ha sido analizado por la historiografía de las migraciones. Véase, por ejemplo, CANCIAN y WeGGE, "If it is not too expensive". 
al Brasil para hacer compras. Que pasó cinco días en un hotel en Santos y luego ocho en San Pablo, aunque no recordaba los nombres de los hoteles ni de las calles. En la información que la policía filtró a la prensa, quedaba claro que algún soplón le había pasado el dato de sus viajes y de su identidad, ya que las crónicas lo nombraban como "Ricardo Kerry o Chiarini". 52

Sus viajes entre el Río de la Plata y el litoral brasileño continuaron sin cesar. Poco después de ser liberado por falta de pruebas retornó a Buenos Aires y, al año siguiente, las crónicas del "movimiento del puerto" lo captaban llegando a Río de Janeiro en un vapor francés procedente de la capital argentina. Al parecer, esta vez permaneció cinco meses en el Brasil antes de volver a Buenos Aires. ${ }^{53}$ Poco después, en enero de 1907, era detenido de nuevo en Río de Janeiro, esta vez con el nombre falso de Adolfo Piny. La trama de esta detención-que, a diferencia de las anteriores, terminó con el joven Chiarini en prisión- mostraba que ni los intercambios policiales sudamericanos ni la acción vigilante de la red diplomática eran suficientes para seguir las huellas de estos escurridizos circuladores de dinero falso. La principal herramienta eran los soplones que vendían información clave a la policía. Así supieron que, desde Montevideo, llegaba Ricardo Chiarini, descrito en las crónicas como un "individuo todavía joven, bien vestido y de apariencia simpática”, trayendo un enorme stock de dinero falso. ${ }^{54}$

En lugar de detenerlo en el puerto, la policía carioca decidió observar sus pasos. Tenía un dato concreto: Chiarini se iba a

\footnotetext{
52 "Notas falsas", Gazeta de Notícias (25 mayo 1905); "Moedeiro falso?”, A Notícia (26 mayo 1905) y "Moedeiro falso?", Gazeta de Notícias (27 mayo 1905).

53 "Movimento do porto", Correio da Manhã (3 jun. 1906). Según los registros de la base de datos del CEMLA [https://cemla.com/], Ricardo Chiarini entró a la Argentina el 3 de noviembre de 1906 en el vapor Cordillère, proveniente de Río de Janeiro. Consultado el 16 de diciembre de 2019.

54 "Dinheiro falso", O Paiz (20 ene. 1907).
} 
encontrar con un comerciante de San Pablo llamado Benjamín Lopes dos Reis. Al tirar del hilo de ese nombre, surgen algunas pistas para comprender el perfil de estos compradores mayoristas de billetes falsos. Pocos años antes, los diarios anunciaban un remate de toda la mercadería de sus comercios de herramientas y sus almacenes de productos importados. ${ }^{55}$ Todo indica que, ante la bancarrota de su empresa, Lopes dos Reis vio una salida posible en el uso de dinero falso para pagar deudas, proveedores y empleados. En 1905, por ejemplo, una mujer negra llamada Rita fue conducida a una comisaría suburbana, en el barrio de Madureira, luego de ser denunciada por usar un billete falso en una estación de tren. En el interrogatorio, Rita declaró al comisario que recibió ese billete de su patrón, quien también fue llamado a declarar y confesó que lo había recibido del comerciante Benjamín Lopes dos Reis. ${ }^{56}$

Dos años más tarde, Lopes dos Reis y Chiarini hijo pactaron un encuentro en una esquina del Palacio Monroe de Río de Janeiro, para hacer una transacción de billetes falsos a cambio de una suma de dinero legítimo. Cuando Chiarini le pasó el paquete, los agentes de pesquisa dieron la voz de arresto y comenzó una batahola. Las crónicas contaban que la policía "tuvo que distribuir algunos garrotazos para calmar los ánimos”. ${ }^{57}$ Las pruebas recogidas eran contundentes: un paquete de 1300 billetes falsos de 20000 reis, que alcanzaban en total un valor nominal de más de 27 “contos de reis” (forma de llamar al millón de reis); una verdadera fortuna.

Chiarini y Lopes dos Reis intentaron fugarse, pero fue en vano. Fueron detenidos y sometidos a un juicio cuyo expediente se encuentra en el Archivo de la Justicia Federal de Río de Janeiro. Atando los cabos sueltos, es un caso de excepcional riqueza

55 Véase, por ejemplo, “Leilões”, Jornal do Brasil (26 jun. 1903).

56 "Dinheiro falso em Madureira”, A Noticia (19 ene. 1905) y "Ainda notas falsas”, A União (20 mayo 1905).

57 “Dinheiro falso", O Paiz (20 ene. 1907). 
para reconstruir todos los eslabones de la cadena del negocio: desde la negra Rita -trabajadora pescada en la incómoda situación de usar un billete falso para adquirir un pasaje de tren- se llegaba a su patrón y, mediante su testimonio, al comerciante Benjamín Lopes dos Reis, comprador mayorista que trataba directamente con el distribuidor Ricardo Chiarini, hijo del fabricante de los billetes falsos en el Río de la Plata, Francesco Chiarini.

En las declaraciones testimoniales de los policías que detuvieron a Chiarini quedaba claro que le seguían los pasos desde hacía más de un año y decidieron vigilarlo tras su desembarque en el puerto de Río de Janeiro. Sabían, además, que el sujeto que decía llamarse Adolfo Piny era -en realidad- el hijo del famoso falsificador italiano radicado en Buenos Aires. El primer testimonio de Chiarini, por su parte, era toda una pieza de ficción biográfica: decía ser alemán, soltero y comerciante, hijo de Alfredo Piny y de Magdalena Roi, nacido en la ciudad de Hamburgo 28 años atrás. Sin embargo, tanto en el sumario como en el juicio los agentes policiales parecían poco preocupados por su identidad: resaltaban que era un "pasador" habituado a las “transacciones” con billetes falsos y que "también era conocido en la policía con el nombre de Ricardo Chiarini”. ${ }^{58}$ Por algún motivo, el hijo del falsificador italiano decidió cambiar la estrategia de defensa y, en una audiencia ante el juez, confesó "llamarse Ricardo Chiarini y no Adolfo Piny como dijo a la policía, para no avergonzar a su familia, natural de Italia”. En este testimonio Chiarini parecía reafirmar lo que habían sugerido algunas crónicas de la prensa: atribuía la denuncia que terminó con su detención "a la persecución y venganza de sus enemigos”. ${ }^{59}$

58 AJFRJ, doc. 4522, 2a. Vara Federal, Processo contra Adolpho Peny y Benjamin Lopes dos Reis: Auto de prisão em flagrante (19 ene. 1907), f. 6-14 y Depoimentos das testemunhas (23 feb. 1907), f. 56-81.

59 AJFRJ, doc. 4522, Auto de interrogatório do acusado (5 mar. 1907), f. 82. 
Las estrategias de defensa de Chiarini y Lopes dos Reis, articuladas por el mismo abogado, se enfocaron en la denuncia de un complot entre la policía y sus adversarios en los negocios, sin muchas precisiones ni nombres propios. De poco sirvió: el juez federal primero les negó un habeas corpus y luego los condenó a prisión, basándose en el artículo del Código Penal que castigaba la práctica de "poner en circulación moneda falsa en forma dolosa”. Mientras parte de la prensa gráfica, en sintonía con la versión policial, se esforzaba en mostrarlos como "pasadores" profesionales de billetes falsos que usaban la etiqueta de comerciantes como fachada para el verdadero y criminal negocio, los documentos del proceso judicial admitían otra lectura posible. En el caso de Lopes dos Reis, numerosos portugueses dedicados al comercio en San Pablo se prestaron a firmar una declaración que lo señalaba como un "negociante honrado", mientras que Chiarini mostró como pruebas diversas cartas recibidas de sus proveedores europeos de telas, vinculados a casas comerciales de Milán y París. ${ }^{60}$ La participación de estos inmigrantes en redes comerciales presuponía vínculos basados en la confianza, solidaridades étnicas, redes de parentesco y amistad, pero también involucraba disputas por el dominio de espacios de distribución y venta de mercancías. Todos esos circuitos estaban atravesados por transacciones monetarias y eran, por eso mismo, un terreno ideal para poner en circulación billetes falsos, aunque un terreno minado por competidores que podían transformarse en delatores de la policía. Entre el mundo del comercio y el de la circulación de moneda falsa no había, entonces, una discontinuidad, sino un entramado complejo de usos de dinero legal e ilegal en la búsqueda de conseguir liquidez y lucro en tiempos financieramente turbulentos.

En los años siguientes, los destellos de visibilidad en la vida de Ricardo Chiarini, siempre asociados a problemas con la policía,

60 AJFRJ, doc. 4522, Documentos anexos ao processo, f. 124-129 y 148-150. 
reafirman la conjetura de esas fronteras grises entre el mundo del comercio y la falsificación de dinero. Poco tiempo después de cumplir los dos años de prisión en la Casa de Corrección de Río de Janeiro y previo paso por Buenos Aires, Chiarini fue detenido por la policía carioca. Por el escaso tiempo transcurrido, las crónicas empezaban admitiendo que sus lectores "debían recordar todavía" el caso de 1907 y el nombre de este "monedero falso hijo del monedero falso" Francesco Chiarini, quien también acababa de cumplir su sentencia en la Argentina por el caso de $1899 .{ }^{61}$ A la par de otras celebridades del delito, los Chiarini desfilaban en los diarios apuntados como eslabones de una banda organizada con "casa matriz" en la Argentina y varias "agencias" repartidas por distintas ciudades brasileñas. Una serie de reportajes del Jornal do Brasil trataba de mostrar que Ricardo Chiarini y sus cómplices eran un fragmento de esa red transnacional. Tan vasta era su trama-se explicaba- que por cada dos o tres falsificadores detenidos por la policía había "treinta compañeros" disponibles para sustituirlos. Además, ellos mismos tenían una policía propia, "admirablemente organizada", repleta de espías que vigilaban a los vigilantes de la policía oficial, mientras que esta última usaba la táctica de cautivar "traidores" con promesas de empleo. ${ }^{62}$

La nueva detención de Ricardo Chiarini exponía todas estas facetas del negocio de la moneda falsa. Desde su retorno a Río de Janeiro en marzo de 1910 la policía carioca, avisada por sus pares de Buenos Aires, lo vigilaba de cerca. La necesidad de detenerlo infraganti, mientras se ejecutaba una transacción de billetes falsos, justificó una espera de más de 20 días. Una noche, cuando concretaba una operación en un banco de plaza del barrio de Gloria, escuchó otra vez el grito policial de prisión. De nuevo los hombres con quienes negociaba eran inmigrantes que trabajaban

61 “Derrama de moeda falsa”, Jornal do Commercio (23 abr. 1910).

62 “A polícia dos falsários”, Jornal do Brasil (16 abr. 1910). 
en distintos ramos: un portugués dueño de una taberna y un italiano propietario de una lavandería. ${ }^{63}$ Los diarios de Río de Janeiro publicaron en bloque la misma versión ofrecida por la policía y los mismos retratos de los acusados.

\section{Imagen 2}

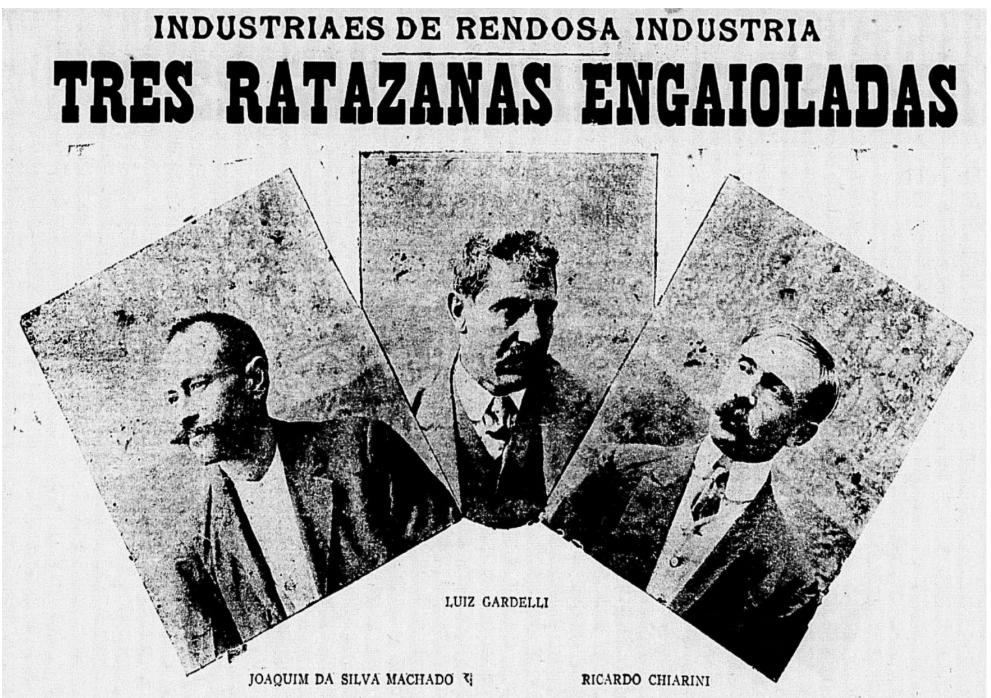

Fuente: Correio da Manhã (16 abr. 1910).

Las solidaridades entre los detenidos se revelaban en la opción por un mismo abogado defensor. El jurista elegido presentó un pedido de habeas corpus por ausencia de orden judicial en la detención, ejecutada por simple mandato de la jefatura de policía. ${ }^{64}$ El juez mandó soltarlos y pudieron esperar en libertad mientras los agentes policiales preparaban el sumario de

63 "Dinheiro falso", O Paiz (15 abr. 1910) y "A polícia dos falsários. Os acusados presos”, Jornal do Brasil (16 abr. 1910).

64 AJFRJ, documento 2328, 1a. Vara Federal, Pedido de Habeas Corpus em favor de Ricardo Chiarini, 1910. 
acusación. Publicado en la revista Boletim Policial y reproducido por varios diarios brasileños, el informe buscaba reforzar la tesis de una banda organizada para fabricar desde el Río de la Plata billetes falsos del Brasil. Según este relato, Chiarini había "confesado sus relaciones con Luis Gardelli, Affonso Coelho, Angelo Evangelista, Jerónimo Pigatti y otros conocidos monederos falsos". No se evocaban nombres al azar. Reconocido por cualquier lector de diarios y gran estrella delictiva de su época, el estafador portugués Affonso Coelho empezaba a ser vinculado en la prensa a esta industria de la falsificación, mientras que los italianos Angelo Evangelista y Jerónimo Pigatti venían siendo protagonistas de crónicas policiales por circulación de billetes falsos. Por último, el italiano detenido junto con Chiarini, Luis Gardelli, era acusado de figurar "en el registro criminal de la Comisaría [de Investigaciones] de Buenos Aires como empresario de delitos de robos y falsificaciones de moneda". ${ }^{65}$

La alusión a la industria de la moneda falsa como un negocio y a sus protagonistas como "empresarios" o "capitalistas" permeaba casi todas las interpretaciones. $\mathrm{Al}$ igual que Caras y Caretas una década antes, cuando Pellicer usaba la expresión "marca Chiarini y Compañía”, en 1910 el periodista del Jornal do Commercio hablaba de la existencia de la firma "Chiarini, Gardelli \& Compañía”. Sin embargo, además de reforzar la versión oficial, parte de la prensa carioca también sugería claves de lectura que el informe policial omitía, especialmente la existencia de un integrante de esta red de negocios que habría traicionado a sus socios y ayudado a la policía. ${ }^{66}$

La interpretación predominante en la policía carioca era la misma que defendía Rossi desde la Comisaría de Investigaciones de Buenos Aires. Elysio de Carvalho, director de la Oficina

65 “1a Delegacia Auxiliar", Boletim Policial, 2 (jun. 1910), p. 31. Sobre la celebridad de Affonso Coelho en la prensa brasileña véase OTTONI, pp. 160-167. 66 “As fábricas de dinheiro", O Século (23 abr. 1910) y "Derrama de moeda falsa", Jornal do Commercio (23 abr. 1910). 
de Identificación de Río de Janeiro encargada de los canjes de informaciones policiales con la Argentina, ponía a los falsificadores como ejemplo de los "especialistas del ejército del delito, que ejecutaban solamente determinado género de trabajo" y que "nunca trabajaban solos, sino asociados a otros individuos de su especie". ${ }^{67}$ En los mismos años en que Ricardo Chiarini distribuía billetes falsos en el Brasil y pasaba estadías en la prisión de la capital, Carvalho publicó varios textos sobre el fenómeno delictivo de la falsificación de dinero. En todos reafirmaba la idea de la existencia de una "industria bien organizada, muy rentable y practicada en gran escala”, con fábricas localizadas en Buenos Aires y Montevideo. No obstante, los propios nombres que citaba como ejemplos -entre ellos, supuestos cómplices de Chiarini como Ángelo Evangelista- eran detentores de prontuarios policiales que contradecían su teoría de los delincuentes profesionales dedicados siempre a la misma especialidad. ${ }^{68}$

Dentro de esta red delictiva, el lazo que ataba al distribuidor Ricardo Chiarini con los fabricantes de billetes falsos que, según la policía, operaban desde el Río de la Plata, conducía a un espacio de inmigrantes expertos en fotografía y grabado. Pero hacia los márgenes de la red, la puesta en circulación de esos mismos billetes contaba con la participación de pequeños "pasadores" que tenían antecedentes delictivos como ladrones, estafadores y contrabandistas, como Gardelli, Pigatti y Evangelista. El caso Chiarini ofrece pistas para comprender cómo se forjaban esos vínculos entre fabricantes, distribuidores y circuladores de dinero falso: todo apunta hacia adentro de la prisión. Entre 1907

\footnotetext{
${ }^{67}$ Carvalho, A polícia carioca, pp. 107-108.

${ }^{68}$ Carvalho, A falsificação dos nossos valores circulantes y "Moeda falsa", Careta, 210 (8 nov. 1912). Una copia del prontuario de Evangelista se encuentra en el legajo de su proceso de expulsión del Brasil en 1928. En ese momento, con 42 años, contaba con 14 entradas en la prisión, la mayoría por robos y estafas. ANB, IJJ7-127, Proceso de expulsión de Ángelo Evangelista (17 de febrero de 1928).
} 
y 1914, Ricardo Chiarini pasó casi todo el tiempo en la cárcel de Río de Janeiro. A la primera condena de dos años se le sumó otra de cuatro en 1910: el aumento del castigo se debía a una nueva ley contra la falsificación, sancionada en septiembre de 1909, que agravaba en Brasil la pena máxima contra circuladores de billetes falsos. ${ }^{69}$

Como en la vez anterior, al cumplir su condena en 1914 Chiarini tardó poco tiempo en caer preso de nuevo. Aunque ahora la denuncia era por contrabando de joyas, el episodio mostraba que, lejos de un tiempo muerto de aislamiento, los días en prisión eran fructíferos en el hilvanado de redes de negocios. $\mathrm{Ni}$ bien abandonó la Casa de Corrección, Chiarini fue a trabajar como gerente en una joyería muy bien ubicada sobre la Avenida Río Branco, cuyo propietario era Charles Grassy. Los antecedentes policiales de este migrante francés mostraban pasos por la Penitenciaría Nacional de Buenos Aires en los mismos años en que Francesco Chiarini cumplía condena y también en la cárcel de Río de Janeiro que alojó a su hijo Ricardo. En uno de los robos que lo puso tras las rejas, en 1906, Grassy fue detenido junto con Gardelli, el italiano que cuatro años más tarde caería preso junto con Chiarini. ${ }^{70}$ Todos estos nombres, que se repiten y se entrecruzan en distintas coyunturas, parecen tener en la prisión el principal espacio de encuentro. Entre los falsificadores, escribía un cronista porteño en 1899 , la cárcel no pasaba de ser una "detención cómoda, que generalmente sirve para que se perfeccionen en el arte que cultivan". ${ }^{71} \mathrm{La}$ experiencia del encierro no era nada confortable, como ese mismo año insinuaban los

69 “Decreto n. 2.110, de 30 de setembro de 1909", Diário Oficial da União (5 oct. 1909), p. 7171.

70 "O contrabando de La Royale”, A Rua (28 abr. 1915); “Os fraudadores do fisco", A Notícia (28 abr. 1915) y "Contrabando de joias", Jornal do Brasil (29 abr. 1915).

71 "La falsificación de billetes. Por qué se reproduce", La Prensa (26 mar. 1899). 
esfuerzos de Francesco Chiarini para evitar que su hijo terminara tras las rejas, pero los indicios sobre negocios urdidos en interacciones carcelarias son contundentes.

Chiarini y Grassy se habían aproximado en la prisión, al igual que los circuladores de dinero falso Gardelli, Evangelista y Pigatti. En 1917, uno de los más famosos falsificadores de dinero del Brasil, el migrante portugués Albino Mendes, fue interrogado por la policía carioca en la Casa de Corrección. El motivo era un escándalo desatado cuando se descubrieron billetes falsos producidos dentro de la prisión, como había sucedido en la Penitenciaría Nacional de Buenos Aires con Francesco Chiarini. El falsificador portugués no negó su participación en la fabricación de los billetes, pero aseguró que se trataba de ensayos lúdicos y no de dinero para poner en circulación. Cuando le preguntaron cómo había conseguido los materiales (papel, películas, tintas, clichés), respondió que se los había entregado "un preso [llamado] Ricardo o Francisco Chiarini, detenido por delito de introducción de moneda falsa", aunque en ese momento ya había salido de prisión y su paradero era desconocido. Los agentes policiales quisieron entender la forma en que Chiarini había reunido todo ese material en la cárcel y, si bien Albino Mendes esquivaba la mayor parte de las preguntas, reconoció que "su compañero de presidio era constantemente visitado por amigos". ${ }^{72}$

Por averiguaciones con la policía de Buenos Aires, que demostraban que Chiarini estaba instalado hacía un tiempo en la Argentina, los investigadores brasileños desestimaron la versión del falsificador portugués y apuntaron las sospechas contra los guardias de la Casa de Corrección. Sin embargo, la propia mención del clan Chiarini en la declaración testimonial de Albino Mendes, a través de la disyunción lógica que aludía al nombre

72 “A última... de Albino Mendes”, A Rua (25 ago. 1917) y “Albino Mendes em foco", Gazeta de Notícias (26 ago. 1917). 
del padre y del hijo ("Ricardo o Francisco Chiarini"), puede ser interpretada en su verosimilitud. Inventada para engañar o no, lo cierto es que al propio Albino Mendes le pareció una respuesta adecuada para los oídos de los agentes policiales que, al menos al comienzo, la creyeron lo suficientemente plausible como para transmitirla a la prensa.

Las huellas de Ricardo Chiarini podrían seguirse más allá de la década de 1910, aunque se tornan más tenues. En 1922 el médico del trasatlántico Alegrete recibió billetes falsos en el puerto de Recife y diferentes fuerzas policiales del nordeste del Brasil iniciaron una investigación coordinada. La policía de Bahía logró detener al supuesto pasador, un tal Antonio Godim, al que le secuestró abundante correspondencia con otros cómplices, integrantes de lo que fue narrado como una "banda de falsificadores esparcida por varios estados brasileños". Entre la serie de allanamientos y prisiones, la policía del estado de Alagoas detuvo a Chiarini en un hotel de la ciudad de Maceió, pero al año siguiente la justicia federal lo absolvióo. ${ }^{73}$ Desde esos comienzos de la década de 1920 hasta los primeros años de la década de 1940, los registros de pasajeros de los puertos muestran frecuentes viajes de Chiarini entre Río de Janeiro, Santos, Montevideo y Buenos Aires, siempre anotado en los libros como italiano, casado, comerciante, católico y, en general, pasajero de primera clase.$^{74}$ Como un hombre de negocios, casi siempre viajaba solo y se hospedaba en buenos hoteles.

Sus pasos no sólo conducen al trazado de un enmarañado mapa de ciudades atlánticas, sino también a un laberinto de

73 "O caso das notas falsas recebidas pelo médico do Alegrete", A Noite (13 nov. 1922) e "Interior. Alagoas", Gazeta de Notícias (3 mar. 1923).

${ }^{74}$ Utilizando las bases de datos del CEMLA y del Family Search fue posible reconstruir 17 viajes de Ricardo Chiarini entre 1922 y 1941 registrados en los libros de entrada de navíos en los puertos de Buenos Aires y Montevideo, cuyos originales se encuentran en los Archivos Nacionales de Argentina y Brasil. Consultado el 20 de diciembre de 2019. 
rostros de inmigrantes europeos detenidos numerosas veces por pasar billetes falsos. Arturo Orcessi, Francisco Stumbo, Benjamín Lopes dos Reis, Luis Gardelli, Affonso Coelho, Angelo Evangelista, Jerónimo Pigatti: los nombres se repiten y se cruzan, componiendo distintas redes de circulación de dinero falso, algunas de las cuales, en parte por su fracaso, pueden ser reconstruidas por la documentación policial y judicial, mientras otras tantas seguramente quedaron enterradas en el silencio de un negocio exitoso. La repetición de nombres en las fuentes documentales es un hecho innegable, pero no es un dato que confirme la existencia de una banda organizada, como le gustaba decir a la policía. Es más bien esta red ubicua y discontinua, repleta de acuerdos y traiciones, confianzas y sospechas, lo que surge por detrás del nombre de Ricardo Chiarini y de sus numerosos pseudónimos que -según apuntaba un cronista de la Gazeta de Notícias- sumaban "más nombres que Edmundo Dantés del Conde de Montecristo”. ${ }^{75}$

\section{PALABRAS FINALES}

En torno al nombre del padre y del hijo, Francesco y Ricardo Chiarini, se vislumbra un mercado trasnacional de billetes falsos, así como una red de negocios atravesada por distintas solidaridades y formas de construcción de confianza. La fabricación de esos billetes involucraba complejos procesos técnicos de fotograbado e impresión offset, que requerían de especialistas en fotografía y manejo de máquinas de prensa. De la puesta en circulación, en cambio, participaban intermediarios que se desempeñaban como distribuidores mayoristas de los billetes falsos y comerciantes que ingresaban a estas redes como compradores. Las evidencias analizadas indican que entrar en este negocio no significaba una renuncia al oficio de fotógrafo, grabador,

75 “Grande contrabando”, Gazeta de Notícias (29 abr. 1915). 
tipógrafo o vendedor, convirtiéndose en un delincuente profesional que sólo vivía de la industria del crimen.

Muchos de los sujetos mencionados a lo largo del artículo alternaban distintas actividades comerciales con las oportunidades de liquidez que les ofrecía el mercado del dinero falso. Liquidez rápida pero riesgosa. Los pasos por las prisiones eran frecuentes y numerosos, pero la reincidencia en el delito no debe ser leída -a la manera de la policía- tan sólo como una monomanía de delincuente profesional, sin tener en cuenta que podía y solía convertirse en una actividad lucrativa en momentos de escasez de dinero circulante. En ese sentido, Marco Severi, la obra teatral imaginada por Roberto Payró y estrenada en 1905, organizaba a sus espectadores estos hilos sueltos del mercado de la falsificación que, muy probablemente, conocieran de las crónicas policiales. Pero lo hacía de una forma que establecía un corte radical entre la vida pretérita de un falsificador de billetes y su presente honrado como trabajador de una imprenta. Trayectorias como la del clan Chiarini, que se cruzan con otros nombres repetidos en los mismos archivos, sugieren que esa discontinuidad no existía fuera de bambalinas.

Los lazos de parentesco y las solidaridades étnicas que servían de pilares en este negocio de la moneda falsa revelan líneas de continuidad con otras historias de inmigrantes. Las trayectorias de distintos falsificadores europeos en América del Sur, mencionadas tangencialmente a lo largo de este artículo, refuerzan ese argumento. El fotógrafo Georges Raimbault, arribado a la Argentina pocos años antes que Francesco Chiarini, se inició en este delito dentro de una banda conformada por otros migrantes franceses en 1894. Después de experiencias frustradas y largos años de cárcel, continuó en el negocio con la ayuda de sus dos hijos varones, nacidos en Buenos Aires, quienes como Ricardo Chiarini se encargaron de la distribución del dinero falso en el Brasil. A comienzos del siglo xx, Albino Mendes dio sus primeros pasos en la falsificación con socios de su misma 
nacionalidad, todos migrantes portugueses radicados en Río de Janeiro. Por su parte, la vida del siciliano Giuseppe Morello, que se hizo conocida por transformarse en el jefe de una de las primeras familias de la mafia italoamericana, muestra trazos similares. Al igual que Chiarini, Morello huyó de Italia en los primeros años de la década de 1890 para evitar una condena de la justicia. En Nueva York se juntó con otros sicilianos y con un impresor napolitano (conocido como "El Profesor") para fabricar billetes falsos de Canadá y Estados Unidos, delito por el que cayeron todos presos en $1910 .^{76}$

Los ejemplos podrían seguir de una costa a la otra del mundo atlántico. Desde América del Sur, el clan Chiarini y otros casos paralelos sugieren que, en tiempos de crisis financiera, cuando los comerciantes quedaban en situaciones de dramática iliquidez, sin efectivo para pagar acreedores, proveedores, ni salarios de sus empleados, la falsificación de dinero se convertía en un buen negocio. Los indicios de la conexión entre el mundo del comercio y el delito de falsificación de moneda son abundantes. En los mismos años en que el comisario Otamendi atribuía a los italianos la costumbre de vender billetes falsos cuando el dinero escaseaba en el mercado argentino y que el periodista Pellicer ironizaba con el "comerciante fundido" como estereotipo de cliente de este negocio, el criminólogo Antonio Dellepiane observaba, en un pasaje dedicado a las tentaciones delictivas de determinadas profesiones y ramos de la economía legal: "los comerciantes cuyos negocios andan mal se sienten inclinados a procurarse fondos por medio de una falsificación". ${ }^{77} \mathrm{El}$ comisario, el periodista y el criminólogo escribían para públicos muy diferentes, pero daban señales de un mismo fenómeno, que las fuentes policiales, judiciales y diplomáticas tienden a corroborar.

76 Galeano, "Un artista del delito" y Lupo, The Troo Mafias, pp. 21-27.

77 Dellepiane, Las causas del delito, p. 182. 
Esos documentos también muestran toda una trama de intercambios transnacionales entre las autoridades que buscaban combatir este delito movedizo. Sea para evadirse de la justicia o reconstruir redes de negocios lejos de la vigilancia policial, estos europeos con conocimientos en las artes gráficas supieron utilizar sus mapas del espacio atlántico, las mismas rutas y los mismos navíos por los que circulaba la migración, para distribuir billetes falsos y ganar a cambio dinero verdadero.

\section{SIGLAS Y REFERENCIAS}

AHI Arquivo Histórico do Itamaraty, Ministerio de Relaciones Exteriores, Río de Janeiro, Brasil.

ANB Arquivo Nacional do Brasil, Río de Janeiro, Brasil.

AJFRJ Arquivo Judiciário, Justiça Federal da $2^{\circ}$ Região, Río de Janeiro, Brasil.

AMRE Archivo Ministerio de Relaciones Exteriores de Argentina, Buenos Aires, Argentina.

CEMLA Centro de Estudios Migratorios Latinoamericanos, Buenos Aires, Argentina.

BAIly, Samuel, "Hacer la América: los italianos ganan dinero en Buenos Aires y New York, 1880-1914”, en Estudios Migratorios Latinoamericanos, 13: 38 (1998), pp. 57-67.

BJerg, María y Hernán Otero (coords.), Inmigración y redes sociales en la Argentina moderna, Buenos Aires, Centro de Estudios Migratorios Latinoamericanos, 1995.

Bjerg, María, "Matrimonios malogrados y pasiones iracundas: inmigrantes en la justicia criminal. Ciudad de Buenos Aires, 1900-1920”, en Historia y Justicia, 11 (2018), pp. 42-67.

Borges, Marcelo, Correntes de Ouro. Emigração Portuguesa para a Argentina em Perspectiva Regional e Transatlântica, Lisboa, Imprensa de Ciências Sociais, 2018.

Borges, Marcelo y Sonia Cancian (eds.), Emotional Language, Mobile Identities, and Writing Practices in Historical Perspective, Londres, Routledge, 2018. 
Bunker, Steven, “Le vol avec homicide de la bijouterie 'La Profesa': Mémoire d'un crime commun”, en Pérez Siller y Lassus (dir.), 2015.

Caimari, Lila y Máximo Sozzo (coords.), Historia de la cuestión criminal en América Latina, Rosario, Prohistoria, 2017.

Cancian, Sonia y Simone Wegge, "If it is not too expensive, then you can send me sugar': Money matters among migrants and their families", en BorGES y CANCIAN (eds.), 2018, pp. 70-87.

Carvalho, Elysio, A polícia carioca. A criminalidade contemporânea, Río de Janeiro, Imprensa Nacional, 1910.

Carvalho, Elysio, A falsificação dos nossos valores circulantes, Río de Janeiro, Imprensa Nacional, 1912.

Catanzaro, Raimondo, El delito como empresa. Historia social de la mafia, Madrid, Taurus, 1992.

Ceva, Mariela, "Inmigración y familia. Una mirada desde las redes de inmigrantes italianos en la Argentina”, en Vendrame, Karsburg y Staudt Moreira (orgs.), 2016, pp. 269-290.

Creazzo, Giuditta, El positivismo criminológico italiano en la Argentina, Buenos Aires, Ediar, 2007.

Dellepiane, Antonio, Las causas del delito: tesis para optar al grado de Doctor en Jurisprudencia, Buenos Aires, Imprenta Coni, 1892.

Devoto, Fernando, Historia de la inmigración en la Argentina, Buenos Aires, Sudamericana, 2009.

Fausto, Boris, Crime a cotidiano. A criminalidade em São Paulo (1880-1924), São Paulo, Edusp, 2001.

Fernández-Bravo, Álvaro, Florencia Garramuño y Saúl Sosnowski (coords.), Sujetos en tránsito: (in)migración, exilio y diáspora en la cultura latinoamericana, Buenos Aires, Alianza, 2003.

Galeano, Diego, "Un artista del delito: circulación de dinero falso entre el Río de la Plata y el Brasil, 1899-1911”, en Caimari y Sozzo (coords.), 2017, pp. 195-233. 
Galeano, Diego, Delincuentes viajeros. Estafadores, punguistas y policías en el Atlántico sudamericano, Buenos Aires, Siglo Veintiuno Editores, 2018.

Galeano, Diego, “'Ese derrame extraordinario': detectives policiales, periodistas y falsificadores de dinero en América del Sur (años 1910)", en Diálogo Andino, 60 (2019), pp. 71-83.

Gambetta, Diego, La mafia siciliana. El negocio de la protección privada, México, Fondo de Cultura Económica, 2007.

Gelman, Jorge (ed.), La historia económica argentina en la encrucijada: balances y perspectivas, Buenos Aires, Prometeo, 2006.

Hоввs, Dick, Doing the Business: Entrepreneurship, the Working Class, and Detectives in the East End of London, Oxford, Clarendon Press, 1988.

Johnson, David, Illegal Tender. Counterfeiting and the Secret Service in Nineteenth-Century America, Washington, Smithsonian Institution Press, 1995.

LAERA, Alejandra, "Representaciones obliteradas: inmigrantes y extranjeros en la novela popular argentina del siglo xIx", en FERnÁndez-Bravo, GarraMUÑO y SosNowsKI (coords.), 2003, pp. 231-253.

Lupo, Salvatore, The Two Mafias: A Transatlantic History 1888-2008, Nueva York, Palgrave Macmillan, 2015.

Ministerio de Hacienda de la Nación, Leyes, decretos y resoluciones sobre la moneda, bancos y Caja de Conversión, t. 1, Buenos Aires, Talleres Gráficos de G. Pesce, 1926.

Otero, Hernán, Historia de los franceses en la Argentina, Buenos Aires, Biblos, 2012.

OtToni, Ana, "O paraíso dos ladrões: crime e criminosos nas reportagens policiais da imprensa (Rio de Janeiro, 1900-1920)", tesis de doctorado en historia, Niterói, Universidade Federal Fluminense, 2012.

PaYró, Roberto, Marco Severi: drama en tres actos, Buenos Aires, Casa Editora de M. Rodríguez Giles, 1907.

Pérez Siller, Javier y Jean-Marie Lassus (dir.), Les Français au Mexique XVIII $-X X I^{e}$ siècle, vol. 2, París, L'Harmattan, Université de Nantes, 2015. 
Policía de la Capital Federal, Memoria del año 1893-1894, Buenos Aires, Imprenta y Encuadernación de la Policía de la Capital, 1894.

Ramella, Franco, "Por un uso fuerte del concepto de red en los estudios migratorios", en BJERG y OTERo (coords.), 1995, pp. 9-21.

Regalsky, Andrés, "Modernización, expansión y crisis: una aproximación a la historiografía de las finanzas, la moneda y el crédito entre 1860 y 1930", en Gelman (ed.), 2006, pp. 101-117.

Rossi, José Gregorio, "La criminalidad profesional en Buenos Aires”, en Archivos de Psiquiatría y Criminología (1902), pp. 169-176.

Salvatore, Ricardo, "Sobre el surgimiento del estado médico-legal en la Argentina (1890-1940)”, en Estudios Sociales, 11 (2001), pp. 81-114.

SCarzanella, Eugenia, Ni gringos ni indios. Inmigración, criminalidad y racismo en la Argentina, 1890-1940, Bernal, Universidad de Quilmes, 2015.

Sozzo, Máximo, “'Los exóticos del crimen’: inmigración, delito y criminología positivista en la Argentina (1887-1914)”, en Delito y Sociedad, 32 (2016), pp. 19-52.

Suprema Corte de Justicia de la Nación, Fallos de la Corte Suprema de Justicia (79), Buenos Aires, Imprenta y Casa Editora Coni, 1901.

Vendrame, Maíra, O poder na aldeia. Redes sociais, honra familiar e práticas de justiça entre os camponeses italianos (Brasil-Itália), São Leopoldo, Oikos, 2016.

Vendrame, Maíra, Alexandre Karsburg y Paulo Staudt Moreira (orgs.), Ensaios de micro-história, trajetórias e imigração, São Leopoldo, OikosUnisinos, 2016.

Zelizer, Viviana, The Social Meaning of Money. Pin money, poor relief $\mathcal{E}$ other currencies, Nueva York, Basic Books, 1994. 